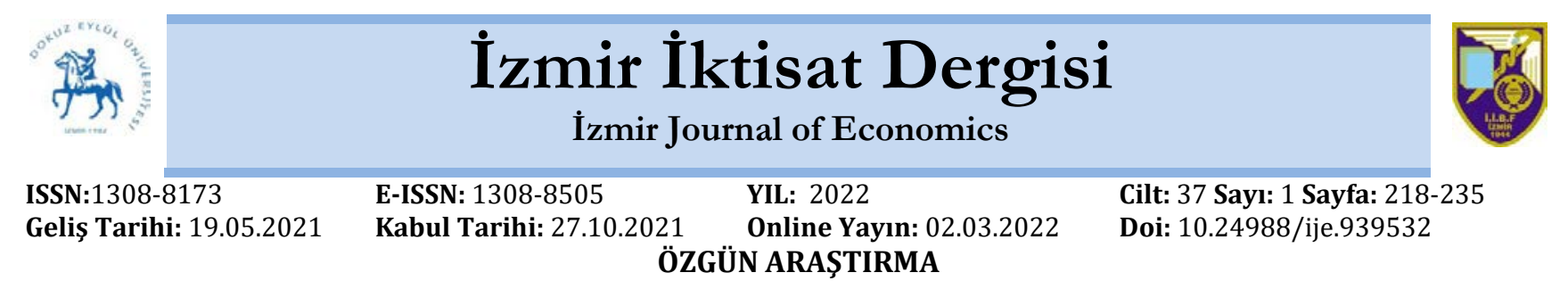

\title{
BIST Sigorta Endeksinde CRITIC Ve MULTIMOOSRAL Tekniklerine Dayalı Finansal Analiz \\ Osman PALA 1
}

Özet

Finansal performans analizi sektörel bazda firmaların etkinliğinin bir ölçütü olarak görülmektedir. Firmaların rekabet edebilir yapıda olması finansal açından başarılı olmaları ile doğru orantılı olmaktadır. Birden çok finansal oranın bir arada değerlendirmesi ile gerçekleșen analiz, bu bağlamda Çok Kriterli Karar Verme problemi olarak adlandırlabilmektedir. Çalışma kapsamında BIST Sigorta Endeksi dahilinde bulunan firmaların finansal performans analizi gerçekleştirilmiştir. $\mathrm{Bu}$ alanda sıklıkla kullanılan finansal oranların önem değerleri, objektif bir değerlendirme yaklaşımı olan CRITIC ile önceliklendirilmiștir. Sonuçlarda karlılık oranları önem bakımından öne çıkarken değerlendirme periyodu açısından değerlerin yakın olduğu gözlenmiștir. Firmaların performans sıralamaları ise beș farklı sıralama yaklașımını birlikte kullanan MULTIMOOSRAL yaklaşımı ile gerçekleştirilmiştir. Finansal performans analizi sonuçları topluca değerlendirildiğinde önerilen bütünleşik yaklaşımın etkinliğinin yüksek olduğu gözlenmiștir.

Anahtar kelimeler: CRITIC, MULTIMOOSRAL, BIST Sigorta, finansal performans.

Jel Kodu: C44,G00, L25.

\section{Financial Analysis Based on CRITIC and MULTIMOOSRAL Techniques in BIST Insurance Index Abstract}

Financial performance analysis is seen as a measure of the efficiency of companies on a sectoral basis. The fact that companies are competitive is directly proportional to their financial success. Analysis performed by evaluating multiple financial ratios together can be named as Multi Criteria Decision Making problem in this context. Within the scope of the study, the financial performance analysis of the companies included in the BIST Insurance Index was performed. The importance values of financial ratios, which are frequently used in this field, have been prioritized by CRITIC, an objective evaluation approach. While profitability rates stand out in terms of importance in the results, it has been observed that values are close in terms of the evaluation period. The performance rankings of the companies were made with the MULTIMOOSRAL approach, which uses five different ranking approaches together. When the results of the financial performance analysis are evaluated collectively, it is observed that the efficiency of the proposed integrated approach is high.

Keywords: CRITIC, MULTIMOOSRAL, BIST Insurance, financial performance.

Jel Codes: C44,G00, L25.

ATIF ÖNERİsí (APA): Pala, O. (2022). BIST Sigorta Endeksinde CRITIC Ve MULTIMOOSRAL Tekniklerine Dayalı Finansal Analiz. İzmir Iktisat Dergisi. 37(1). 218-235. Doi: 10.24988/ije.939532

${ }^{1}$ Arş. Gör. Dr., Karamanoğlu Mehmetbey Üniversitesi, İktisadi ve İdari Bilimler Fakültesi, Merkez/ KARAMAN, EMAIL: osmanpala@kmu.edu.tr ORCID: 0000-0002-2634-2653 


\section{GíRiş}

Bir ekonomide işletmelerin veya kişilerin yüksek kayıp olasılıklarından korunmak ve bu durumun gerçekleşmesi halinde en düşük düzeyde etkilenmek adına başvurdukları bir koruma yaklaşımı olan sigorta başarılı bir güvenlik sistemidir. Belirli prim ödemesi ile sağlanan sigorta hizmeti olası büyük maddi zararları ilgili kişi veya firmanın üzerinden alarak tüm ekonomiye pay eden bir yaklaşıma sahiptir. Bu yönden oluşabilecek hasarın büyüklüğüne göre bazı durumlarda müșterilerini iflasın eşiğine getirebilecek zararlardan koruması ile ekonomide istikrarı sağlayan önemli yapılardan birisi de sigortacılık şirketleridir. Öte yandan topladığı primleri finans alanında değerlendirerek ekonomiye uzun dönemli kaynak aktarmaktadır (Altan ve Yıldırım, 2019: 347). Sigorta firmaları hem gelişmiş hem de gelişmekte olan ülke ekonomilerinde bireylerin düzenli ve etkili bir biçimde tasarruf yapmasını sağlarken aynı zamanda oluşturdukları fonlarla ülkede yatırımların gerçekleşmesine destek olmaktadırlar (Işık, 2019: 543). Türkiye ekonomisinin finansal yapısı içindeki büyüklüğü sürekli artış göstermekte olan sigorta sektörü aynı zamanda ekonomik kalkınmaya pozitif etki sağlamaktadır. Sigorta firmaların etkinliğinin yüksekliği ile sigortacılık sektörünün sağladığı faydanın doğru orantılı olması nedeniyle sigorta işletmelerinin finansal performanslarının analizinin gerçekleştirilmesi ve olası iyileștirme hedeflerinin altının çizilmesi, sektörün istikrarı ve hizmet alıcılarının güveni açısından oldukça önemlidir (Ünal, 2019: 556).

Bu çalışmada, BIST sigorta endeksine tabi olan işletmelerin finansal oranlar kullanılarak etkin bir şekilde finansal performans değerlendirilmesi amaçlanmaktadır. Bu amaçla Çok Kriterli Karar Verme (ÇKKV) modeli olarak ele alınan problemdeki kriterler, hem kriterler arası korelasyon hem de kriter içi sapmaları birlikte ele alan yaklaşım olan CRITIC (Criteria Importance Through Intercriteria Correlation) yardımıyla önceliklendirilmiştir. Öte yandan performans sıralamaları ise Türkçe alan yazında daha önce hiç kullanılmamış ve beş temel hesaplama tekniğinden yararlanan MULTIMOOSRAL (Multi-Multi-Objective Optimization on the basis of Simple Ratio Analysis) ile gerçekleştirilmiştir. Yöntemin daha önce finansal performans alanında kullanılmamış olması ve CRITIC gibi bir objektif kriter ağırlıklandırma yaklaşımıyla bütünleşik olarak ilk defa kullanılması, çalışmanın literatüre katkısı olarak değerlendirilmektedir.

Çalışmanın geri kalan kısmında ise bölüm 2'de sigortacılık sektörü tarihsel gelişimi ve geldiği nokta konusunda bilgiler, bölüm 3'te sigortacılık sektöründeki finansal performans analizi ve bu çalışmada kullanılan yöntemlere dahilinde literatür, bölüm 4'te çalışmadaki yöntemlerin aşamaları, bölüm 5'te önerilen metodun sigortacılık sektöründeki uygulaması, bölüm 6'da kriter ağırlıkları açısından duyarlılık analizi ve son bölümde sonuçlar yer almaktadır.

\section{SIGORTACILIK SEKTÖRÜ}

Sigortacılığın tarihine bakıldığında, günümüz sigorta anlayışından farklılık gözetse de ilk sigorta faaliyet örnekleri Antik Yunan ve Çin'de görülmüştür. Çok eskilere dayanan bu sektör, insanların hayatta karşılaştıkları riskleri minimize etmeye ve insan için çok önemli bir ihtiyaç olan güveni verme üzerine inşa edilmiştir (Yayla, 2019: 109).

Modern şekliyle sigortacılık ise ilk deva kıta Avrupa'sında bir sektör halini almış ve gelişen ticaret yolları ile deniz ve karada sigortacılık faaliyetleri, lojistik ve ticaretin karşılaştıkları sorunlar nedeniyle yaşadıkları büyük kayıpları telafi etme işlevi görmüşlerdir (Yayla, 2019: 109-110).

Gelişmekte olan ekonomiye sahip ülkemiz topraklarında ise modern anlamda sigortacılığın başlangıcı İngiliz şirketlerinin 1872 senesinde sigortacılık faaliyetlerine girişmesi ile gerçekleşmiştir. İlerleyen dönemlerde yapılan kanunlar ve sigorta enstrümanlarında elde edilen çeşitlilikle her duruma ve kitleye hitap eden sigortacılık sektörü ülkemizde gelişmiş ve önemli bir finansal sektör haline gelmiştir (Perçin ve Sönmez, 2018: 566). 
Geçmişte karlı bir sektör olarak görülen sigortacılıkta, bankalar ve yatırım fonları gibi farklı oyuncuların sigorta şirketlerinden rol çalmaya başlamasıyla sektörde rekabet artmış ve geleneksel olarak yüksek maliyetlere sahip sektör șirketlerinin tek başlarına ayakta kalması zorlaşmıştır. Bu nedenle günümüzde satın almalar ve birleşmeler ile sigorta şirketleri büyüme ve sektör dişındaki büyük rakipleri ile bu şekilde mücadele yoluna gitmişlerdir (Cummins vd., 1999: 326).

\section{LITTERATÜR}

Literatüre bakıldığında sigortacılık sektörü bağlamında finansal performans analizinde bulunan çalışmalar büyük çoğunlukla ÇKKV teknikleri kullanılarak yapılmış olup öne çıkanlara bakıldığında; Çakır (2016) sigorta şirketlerinin performans ölçümünü iki etapta gerçekleştirmiştir. Finansal oranları ağırlıklandırılmış hedef programlama ile önceliklendirmiş ve akabinde bulanık mantığa dayalı Aralık VIKOR (VIse Kriterijumska Optimizacija I Kompromisno Resenje) yaklaşımıyla sektördeki firmaları sıralamaya tabi tutmuştur. Kula vd. (2016) tarafından yapılan çalışmada sigorta şirketlerinin performans karşılaştırması ÇKKV tekniklerinden Analitik Hiyerarşi Prosesi (AHP) ve Gri İlişkisel Analiz (GİA) kullanılarak gerçekleștirilmiştir. AHP ile kriter olarak belirlenmiş finansal oranlar ağırlıklandırılırken, nihai sıralamalar GİA ile elde edilmiştir. Ömürbek ve Özcan (2016) çalışmalarında sigorta sektöründe faaliyet gösteren firmaların finansal analizlerini MULTIMOORA (Multi-Multi-Objective Optimization on The Basis of Ratio Analysis) yöntemi kullanarak değerlendirmişlerdir. Kriter olarak finansal oranların kullanıldığı çalışmada her bir kriter için eş ağırlıklı yaklaşım tercih edilmiştir. Shen vd. (2016) tarafından yapılan çalışmada Tayvan'da faaliyette bulunan hayat sigortası şirketlerini hibrit DEMATEL tabanlı Analitik Ağ Süreci (DAAS) ve bulanık integral yaklaşımı kullanarak sermaye yapısı, ödeme gücü, operasyonel etkinlik, kazanç sürekliliği ve sermaye etkinliği kriterleri açısından değerlendirmişlerdir. Mandić vd. (2017) bulanık AHP ve bulanık TOPSIS yöntemleri ile sigorta şirketlerini beş farklı kriter üzerinden finansal performansları açısından değerlendirmişlerdir. Bulanık AHP ile kriter ağırlıklandırma gerçekleştirilirken, bulanık TOPSIS ile nihai sıralama elde edilmiştir. Aytekin ve Karamaşa (2017) Bulanık Entropi ile finansal analizde kullandıkları altı adet finansal oranın önem derecelerini belirlerken sigorta şirketlerini Bulanık TOPSIS (Technique for Order Preference by Similarity to Ideal Solution) aracılığıyla değerlendirmişlerdir. Perçin ve Sönmez (2018) tarafından yapılan çalışmada karlılık, likitide, faaliyet, ve kaldıraç tipindeki finansal oranları kriter olarak belirledikleri çalışmalarında sigortacılık branşında hizmet sunan işletmelerin finansal performans kıyaslamasını gerçekleştirmişlerdir. Entropi yaklaşımıyla kriterleri ağırlıklandırırken TOPSIS ile nihai sıralama elde edilmiştir. Tayyar vd. (2018) AHP ile önceden belirlenmiş finansal oran ağırlıklarına göre sigorta şirketlerinin finansal performans ölçümlerini Referans İdeal Metodu (RIM) kullanarak elde etmişlerdir. Sonuç olarak finansal performans analizinde RİM yaklaşımının etkin bir ÇKKV olduğunun altı çizilmiştir. Torbati ve Sayadi (2018) İran'da yer alan sigorta şirketlerinin performanslarını belirleyen kriterleri En iyien kötü ve bulanık çıkarım sistemi yaklaşımlarını bir arada kullanarak belirlemişlerdir. Acar (2019) tarafından finansal oranlar yardımıyla Borsa İstanbul (BIST) sigorta endeksinde yer alan firmaların performans analizi yapılmıștır. Kriter ağırlıkları ve firma performans sıralamaları TOPSIS yöntemi kullanılarak elde edilmiştir. Altan ve Yıldırım (2019) çalışmalarında sigorta firmalarını ÇKKV tekniklerinden olan TOPSIS ile sıralarken performans analizi için kullanılan finansal oranların ağırlıkları Entropi yaklaşımı ile belirlenmiştir. Işık (2019) çalışmaşında sigorta branşının yıllara göre performansını karşılaștırmıștır. Kriter ağırlıkları CRITIC tekniğiyle belirlenirken, sıralamalar TOPSIS ve MULTIMOORA yaklaşımları ile ayrı ayrı sağlanmıştır. Her iki yönteme göre sıralamalarda anlamlı farklılık bulunan çalışmada en kötü yıllar olan 2012, 2015 ve 2010 için ise uzlaşma sağlanmıştır. Ünal (2019) BIST sigorta endeksinde bulunan firmaların finansal performanslarını bütünleşik Entropi ve EDAS (Evaluation based on Distance from Average Solution) yöntemiyle ölçmüştür. Entropi ile kriter olan finansal oranların önem dereceleri belirlenirken EDAS ile ise problemde alternatif olarak ifade edilen firmalar sıralanmıştır. Dwivedi vd. (2021) tarafından yapılan çalışmada bir sigorta şirketinin 
performansını iki ayrı dönem için incelemiş olup performans değerlendirmede öncelikle dengeli skor kartı kullanarak kriterlere ait tüm şirket işleyişi puanlanmış ve sonrasında nihai değerlendirme ise En iyi-en kötü metodu ile gerçekleştirilmiştir.

Yöntemler açısından literatür incelendiğinde ise, Žižović vd. (2020) CRITIC yönteminde başlangıç matrisi normalizasyonu için ortalama karekök sapmasını azaltan bir öneri ve kriter ağırlık belirlemede ideal değerlere yakın ortalamaya sahip kriterlere öncelik tanıdıkları bir başka öneri, Wu vd. (2020) karşılaştırmalı değerlendirme sonuçlarından oluşan bulut kümeleme verilerinin Z-skoru normalizasyonuna dayanan bir CRITIC yaklaşımı, Zhao vd. (2020) kriterler arasındaki doğrusal olmayan korelasyonu ortaya çıkaran Kopula-CRITIC'i, Krishnan vd. (2021) kriterler arası korelasyonu kriterlerin bağımlılığını da ele alan uzaklık korelasyonu ile değerlendiren bir CRITIC yaklaşımı sunarak klasik CRITIC metodu üzerinde yöntemsel iyileştirme denemelerinde bulunmuşlardır. MULTIMOOSRAL yönteminin ise 2021 yılında önerilen, oldukça yeni bir yaklaşım olması nedeniyle ilerleyen dönemlerde literatürde bulunmaya başlanacağı öngörülmektedir.

\section{YÖNTEM}

Çalışmada ÇKKV problemi olarak ele alınan finansal performans analizinde kriter ağırlıkları CRITIC yaklaşımıyla belirlenirken, sıralama işlemi için MULTIMOOSRAL yönteminden faydalanılmıştır.

\subsection{CRITIC Metodu}

Diakoulaki vd. (1995) tarafından önerilen CRITIC ile kriter ağırlığı hesaplamasına bakıldığında (Jahan vd., 2012: 413):

Öncelikle karar matrisi $X=\left\|x_{i j}\right\|_{\left(n^{*} m\right)}$ alternatifler $A_{i}(i=1, \ldots, n)$ ve kriterler $C_{j}(j=1, \ldots, m)$ için oluşturulmalıdır, akabinde karar matrisi elemanları Eşitlik 1 ve 2 kullanılarak normalize edilmelidir. Burada $x_{j}^{\text {min }}$ ve $x_{j}^{\text {max }}$ kriter $j$ için en düşük ve en yüksek değerleri ifade etmektedir. Sonrasında Eşitlik 3 ve 4 kullanılarak korelasyon katsayıları ve standart sapmalar elde edilmektedir. Son olarak Eşitlik 5 ve 6 ile kriter ağırlığı $w_{j}$ hesaplanmaktadır.

$z_{i j}=\frac{x_{i j}-x_{j}^{\min }}{x_{j}^{\max }-x_{j}^{\min }} \quad$ fayda yönlü kriter

$z_{i j}=\frac{x_{j}^{\max }-x_{i j}}{x_{j}^{\max }-x_{j}^{\min }} \quad$ maliyet yönlü kriter

$\rho_{j k}=\frac{\sum_{i=1}^{n}\left(Z_{i j}-\bar{Z}_{j}\right)\left(Z_{i k}-\bar{Z}_{k}\right)}{\sqrt{\sum_{i=1}^{n}\left(Z_{i j}-\bar{Z}_{j}\right)^{2} \cdot \sum_{i=1}^{n}\left(Z_{i k}-\bar{Z}_{k}\right)^{2}}}, j, k=1, \ldots, m$

$\sigma_{j}=\sqrt{\frac{1}{n} \sum_{i=1}^{n}\left(z_{i j}-\bar{z}_{j}\right)^{2}}, j=1, \ldots, m$

$c_{j}=\sigma_{j} \sum_{k=1}^{m}\left(1-\rho_{j k}\right), j=1, \ldots, m$. 
$w_{j}=\frac{c_{j}}{\sum_{k=1}^{m} c_{k}}, j=1, \ldots, m$.

\subsection{MULTIMOOSRAL Metodu}

Ulutaş vd. (2021) tarafından önerilen ve beş farklı hesaplama tekniğine dayanan MULTIMOOSRAL yaklaşımı aşağıdaki gibi tanımlanmaktadır (Ulutaş vd., 2021: 150-153);

Adım 1: Alternatifler $A_{i}(i=1, \ldots, n)$ ve kriterler $C_{j}(j=1, \ldots, m)$ için karar matrisi $X=\left\|X_{i j}\right\|_{\left(n^{*} m\right)}$ oluşturulmalı ve kriter ağırlıkları belirlenmelidir.

Adım 2: Normalize karar matrisi Eşitlik 7’ye göre hesaplanmaktadır.

$$
r_{i j}=\frac{x_{i j}}{\sqrt{\sum_{i=1}^{n}\left(x_{i j}\right)^{2}}}
$$

Adım 3: Oran sistemi yaklaşımına göre alternatiflerin önem, fayda ve normalize fayda değerleri sırasıyla Eşitlik 8, 9 ve 10'a göre hesaplanmaktadır. Burada Cmaks ve Cmin, kriterin fayda ve maliyet yönlü olduklarını ifade etmektedir.

$$
\begin{aligned}
& y_{i}=\sum_{j \in C \operatorname{cmaks}} w_{j} r_{i j}-\sum_{j \in C \min } w_{j} r_{i j} \\
& m_{i}=\left\{\begin{array}{l}
y_{i}, \quad \operatorname{maks}\left(y_{i}\right)>0, \\
y_{i}+1, \operatorname{maks}\left(y_{i}\right)=0, \\
-1 / y_{i}, \operatorname{maks}\left(y_{i}\right)<0,
\end{array}\right. \\
& m_{i}^{\prime}=\frac{m_{i}-\min \left(m_{i}\right)}{\operatorname{maks}\left(m_{i}\right)-\min \left(m_{i}\right)}
\end{aligned}
$$

Adım 4: Referans noktası yaklaşımına göre alternatif skorlarının hesaplanmasında Eşitlik 11 ile referans noktaları belirlenmekte ve sonrasında her bir alternatif için referans noktalarına maksimum uzaklık Eşitlik 12 ile elde edilmekte ve sonrasında bu değer Eşitlik 13 ile normalize edilmektedir.

$$
\begin{aligned}
& r_{j}^{*}=\left\{\operatorname{maks}_{i} r_{i j} \mid j \in \text { Cmaks, } \min _{i} r_{i j} \mid j \in C \min \right\} \\
& t_{i}=\operatorname{maks}_{j}\left(w_{j}\left|r_{j}^{*}-r_{i j}\right|\right) \\
& t_{i}^{\prime}=\frac{\operatorname{maks}\left(t_{i}\right)-t_{i}}{\operatorname{maks}\left(t_{i}\right)-\min \left(t_{i}\right)}
\end{aligned}
$$

Adım 5: Tam çarpımsal yaklaşıma göre alternatiflerin fayda değerleri Eşitlik 14'e göre hesaplanırken normalize fayda değerleri Eşitlik 15 ile elde edilmektedir.

$u_{i}=\frac{\prod_{j \in C \operatorname{maks}} w_{j} r_{i j}}{\prod_{j \in C \min } w_{j} r_{i j}}$ 
$u_{i}^{\prime}=\frac{u_{i}-\min \left(u_{i}\right)}{\operatorname{maks}\left(u_{i}\right)-\min \left(u_{i}\right)}$

Adım 6: Toplamsal yaklaşıma göre alternatif fayda değerleri ve normalize fayda değerleri sırasıyla Eşitlik 16 ve 17'deki gibi hesaplanmaktadır.

$$
\begin{gathered}
v_{i}=\frac{\sum_{j \in C \operatorname{Cmaks}} w_{j} r_{i j}}{\sum_{j \in C \min } w_{j} r_{i j}} \\
v_{i}^{\prime}=\frac{v_{i}-\min \left(v_{i}\right)}{\operatorname{maks}\left(v_{i}\right)-\min \left(v_{i}\right)}
\end{gathered}
$$

Adım 7: Logaritmik yaklaşıma göre alternatif fayda değerleri ve normalize fayda değerleri ise Eşitlik 18 ve 19 'daki şekilde elde edilmektedir.

$$
\begin{aligned}
k_{i} & =\sum_{j \in C \operatorname{Cmaks}} \ln \left(1+w_{j} r_{i j}\right)+\frac{1}{\sum_{j \in C \min } \ln \left(1+w_{j} r_{i j}\right)} \\
k_{i}^{\prime} & =\frac{k_{i}-\min \left(k_{i}\right)}{\operatorname{maks}\left(k_{i}\right)-\min \left(k_{i}\right)}
\end{aligned}
$$

Adım 8: Alternatiflerin nihai MULTIMOOSRAL sıralamasının elde edilişinde Eşitlik 20 ile beş farklı yaklaşımın normalize değerleri toplanmakta ve en yüksek değere sahip alternatif ilk sırada yer almaktadir.

$$
S_{i}=m_{i}^{\prime}+t_{i}^{\prime}+u_{i}^{\prime}+v_{i}^{\prime}+k_{i}^{\prime}
$$

\section{ARAŞTIRMANIN BULGULARI}

Çalışmada, BIST Sigorta endeksinde yer alan ve sigortacılık sektöründe faaliyet gösteren ve adları Tablo 1'deki gibi olan altı adet firmanın 2019 ve 2020 yılları için finansal performans analizi CRITIC ve MULTIMOOSRAL yaklaşımı ile gerçekleştirilmiştir.

Tablo 1: BIST sigorta endeksi firmaları

\begin{tabular}{|l|l|}
\hline Firma Kodu & Firma Adı \\
\hline AKGRT & Aksigorta A.Ş. \\
\hline ANHYT & Anadolu Hayat Emeklilik A.Ş. \\
\hline ANSGR & Anadolu Anonim Türk Sigorta Şirketi \\
\hline AVISA & Avivasa Emeklilik ve Hayat A.Ş. \\
\hline RAYSG & Ray Sigorta A.Ş. \\
\hline TURSG & Türkiye Sigorta A.Ş. \\
\hline
\end{tabular}

Çalışmada kullanılan finansal oranlar, literatürde yer alan Kula vd. (2016), Ömürbek ve Özcan (2016) ve Perçin ve Sönmez (2018) tarafından sigortacılık sektörü ile alakalı çalışmalarında yer alan temel ve en çok kullanılan finansal oranlardan alınmış olup Tablo 2'de gösterilmiştir. Likidite, kaldıraç, sermaye yapısı ve karlılık finansal performans oran gruplarını eșit temsil edecek şekilde seçilen bu 
oranlardan maksimum yönlü olanlar; F01, F02, F05, F06, F07 ve F08 olurken, minimum yönlü olanlar ise; FO3 ve FO4 şeklindedir.

Tablo 2: Finansal oranlar

\begin{tabular}{|c|c|c|}
\hline Kodu & Oran Adı & Hesaplanış \\
\hline F01 & Cari oran & Dönen Varlıklar/Kısa Vadeli Borçlar \\
\hline F02 & Nakit oran & Nakit ve Nakit Benzerleri / Kısa Vadeli Borçlar \\
\hline F03 & Borç Oranı & Toplam Borç/Toplam Varlık \\
\hline F04 & Kısa Vadeli Borç Varlık Oranı & Net Satışlar / Öz Sermaye \\
\hline F05 & Öz Sermaye Devir Hızı & Net Satışlar / Toplam Varlık \\
\hline F06 & Varlık Devir Hızı & Net Kar/Net Satışlar \\
\hline F07 & Net Kar Marjı & Brüt Satış Karı/Net Satışlar \\
\hline F08 & Brüt Kar Marjı & Karlar \\
\hline
\end{tabular}

Çalışma kapsamında 2020 yılı için tüm işlem adımları paylaşılmış olup 2019 yılı için ise elde edilmiş sonuç değerleri sunulmuştur. Firmalar arası haksız rekabeti önleyebilmek adına firmalar A1-A2-A3A4-A5-A6 şeklinde ifade edilmiştir. Tablo 3'de 2020 yılı için standart karar matrisi yer almaktadır.

Tablo 3: Karar matrisi 2020 yılı

\begin{tabular}{|c|c|c|c|c|c|c|c|c|}
\hline & F01 & F02 & F03 & F04 & F05 & F06 & F07 & F08 \\
\hline A1 & 1.26 & 0.52 & 0.80 & 0.78 & 5.98 & 1.19 & 0.06 & 0.08 \\
\hline A2 & 1.04 & 0.02 & 0.96 & 0.95 & 1.42 & 0.06 & 0.23 & 0.29 \\
\hline A3 & 1.24 & 0.37 & 0.80 & 0.76 & 3.57 & 0.73 & 0.06 & 0.07 \\
\hline A4 & 4.92 & 1.46 & 0.98 & 0.02 & 10.51 & 0.21 & 0.04 & 0.05 \\
\hline A5 & 1.21 & 0.66 & 0.81 & 0.78 & 2.99 & 0.56 & 0.06 & 0.07 \\
\hline A6 & 1.30 & 0.92 & 0.68 & 0.66 & 3.02 & 0.97 & 0.11 & 0.14 \\
\hline
\end{tabular}

CRITIC yöntemiyle finansal oranları önceliklendirmek için Eşitlik 1 ve 2 ile normalize edilmiş karar matrisi Tablo 4'deki gibidir.

Tablo 4: CRITIC yöntemiyle normalize edilmiş 2020 yılı karar matrisi

\begin{tabular}{|l|c|c|c|c|c|c|c|c|}
\hline & F01 & F02 & F03 & F04 & F05 & F06 & F07 & F08 \\
\hline
\end{tabular}




\begin{tabular}{|l|l|l|l|l|l|l|l|l|}
\hline A1 & 0.06 & 0.35 & 0.59 & 0.19 & 0.50 & 1.00 & 0.12 & 0.12 \\
\hline A2 & 0.00 & 0.00 & 0.08 & 0.00 & 0.00 & 0.00 & 1.00 & 1.00 \\
\hline A3 & 0.05 & 0.24 & 0.61 & 0.20 & 0.24 & 0.59 & 0.10 & 0.08 \\
\hline A4 & 1.00 & 1.00 & 0.00 & 1.00 & 1.00 & 0.13 & 0.00 & 0.00 \\
\hline A5 & 0.04 & 0.44 & 0.56 & 0.19 & 0.17 & 0.44 & 0.09 & 0.09 \\
\hline A6 & 0.07 & 0.62 & 1.00 & 0.31 & 0.18 & 0.80 & 0.37 & 0.36 \\
\hline
\end{tabular}

Kriterler arası ilişkileri ifade eden $\rho_{j k}$ elemanlarından oluşan matris ise Tablo 5 'de ifade edilmiştir.

Tablo 5: CRITIC yöntemine göre kriterler arası korelasyon matrisi 2020 yılı

\begin{tabular}{|c|l|l|l|l|l|l|l|l|}
\hline & \multicolumn{1}{|c|}{ F01 } & \multicolumn{1}{|c|}{ F02 } & \multicolumn{1}{|c|}{ FO3 } & \multicolumn{1}{|c|}{ F04 } & \multicolumn{1}{|c|}{ F05 } & \multicolumn{1}{|c|}{ F06 } & \multicolumn{1}{|c|}{ F07 } & F08 \\
\hline F01 & 1.00 & 0.83 & -0.58 & 0.97 & 0.91 & -0.41 & -0.41 & -0.40 \\
\hline F02 & 0.83 & 1.00 & -0.05 & 0.92 & 0.80 & 0.01 & -0.64 & -0.63 \\
\hline F03 & -0.58 & -0.05 & 1.00 & -0.37 & -0.41 & 0.84 & -0.24 & -0.25 \\
\hline F04 & 0.97 & 0.92 & -0.37 & 1.00 & 0.91 & -0.24 & -0.54 & -0.54 \\
\hline F05 & 0.91 & 0.80 & -0.41 & 0.91 & 1.00 & -0.06 & -0.63 & -0.62 \\
\hline F06 & -0.41 & 0.01 & 0.84 & -0.24 & -0.06 & 1.00 & -0.44 & -0.44 \\
\hline F07 & -0.41 & -0.64 & -0.24 & -0.54 & -0.63 & -0.44 & 1.00 & 1.00 \\
\hline F08 & -0.40 & -0.63 & -0.25 & -0.54 & -0.62 & -0.44 & 1.00 & 1.00 \\
\hline
\end{tabular}

Eşitlik 5 ve 6 ile elde edilen $C_{j}$ ve kriterlerin nihai ağırlık değerleri $w_{j} 2019$ ve 2020 yılı için Tablo 6'da olduğu şekilde verilmiştir. Elde edilen kriter ağırlıklarına göre F07 ve F08 her iki yıl içinde en önemli değerlendirme kriterleri olarak ortaya çıkmıştır. 2019 ve 2020 yılları arasında finansal oranların ağırlığı bakımından büyük değişiklikler söz konusu olmamıştır. Bu açıdan CRITIC yöntemi ile kriter ağırlıklandırmanın istikrarlı ve başarılı olduğu görülmektedir.

Tablo 6: CRITIC yöntemine göre kriter ağırlıkları

\begin{tabular}{|l|c|c|c|c|c|c|c|c|}
\hline & F01 & F02 & F03 & F04 & F05 & F06 & F07 & F08 \\
\hline \multicolumn{8}{|c|}{2019 YILI } \\
\hline$C_{i}$ & 2.38 & 2.01 & 2.67 & 2.06 & 2.09 & 2.85 & 3.24 & 3.23 \\
\hline
\end{tabular}




\begin{tabular}{|c|l|l|l|l|l|l|l|l|}
\hline$w_{i}$ & 0.12 & 0.10 & 0.13 & 0.10 & 0.10 & 0.14 & 0.16 & 0.16 \\
\hline Sira & 5 & 8 & 4 & 7 & 6 & 3 & 1 & 2 \\
\hline \multicolumn{7}{|c|}{2020 YILI } \\
\hline$C_{i}$ & 2.18 & 1.80 & 2.75 & 1.88 & 1.99 & 2.72 & 3.03 & 3.04 \\
\hline$w_{i}$ & 0.11 & 0.09 & 0.14 & 0.10 & 0.10 & 0.14 & 0.16 & 0.16 \\
\hline Sira & 5 & 8 & 3 & 7 & 6 & 4 & 2 & 1 \\
\hline
\end{tabular}

MULTIMOOSRAL yaklaşımına göre firmaların sıralamasında ilk önce standart karar matrisi kullanılarak normalize karar matrisi Eşitlik 7'ye göre elde edilmiş ve Tablo 7'de verilmiştir.

Tablo 7: MULTIMOOSRAL yöntemine göre normalize edilmiş 2020 yılı karar matrisi

\begin{tabular}{|c|c|c|c|c|c|c|c|c|}
\hline & F01 & F02 & F03 & F04 & F05 & F06 & F07 & F08 \\
\hline A1 & 0.22 & 0.27 & 0.39 & 0.44 & 0.45 & 0.66 & 0.23 & 0.23 \\
\hline A2 & 0.19 & 0.01 & 0.46 & 0.54 & 0.11 & 0.03 & 0.83 & 0.82 \\
\hline A3 & 0.22 & 0.19 & 0.39 & 0.43 & 0.27 & 0.40 & 0.21 & 0.20 \\
\hline A4 & 0.88 & 0.75 & 0.47 & 0.01 & 0.79 & 0.12 & 0.14 & 0.15 \\
\hline A5 & 0.21 & 0.34 & 0.39 & 0.44 & 0.22 & 0.31 & 0.21 & 0.21 \\
\hline A6 & 0.23 & 0.47 & 0.33 & 0.37 & 0.23 & 0.54 & 0.40 & 0.39 \\
\hline
\end{tabular}

Eşitlik 8, 9 ve 10 kullanılarak elde edilen oran sistemi yaklaşımı önem, fayda ve normalize fayda değerleri ise Tablo 8'de gösterilmiştir.

Tablo 8: Oran sistemine göre 2020 yılı için elde edilen sonuç değerleri

\begin{tabular}{|c|c|c|c|}
\hline & $y_{i}$ & $m_{i}$ & $m_{i}^{\prime}$ \\
\hline A1 & 0.164 & 0.164 & 0.481 \\
\hline A2 & 0.178 & 0.178 & 0.575 \\
\hline A3 & 0.096 & 0.096 & 0.037 \\
\hline A4 & 0.243 & 0.243 & 1.000 \\
\hline A5 & 0.090 & 0.090 & 0.000 \\
\hline A6 & 0.209 & 0.209 & 0.777 \\
\hline
\end{tabular}

MULTIMOOSRAL'da yer alan bir başka değerlendirme yaklaşımı olan referans noktası yöntemine göre öncelikle Eşitlik 11 kullanılarak referans noktaları belirlenmiş olup sonrasında Eşitlik 12 ve 13 ile elde edilen referans noktalarına maksimum uzaklık ve normalize maksimum uzaklık değerleri Tablo 9'da verilmiştir. 
Tablo 9: Referans Noktasına Göre 2020 Yılı İçin Elde Edilen Sonuç Değerleri

\begin{tabular}{|c|c|c|}
\hline & $t_{i}$ & $t_{i}^{\prime}$ \\
\hline A1 & 0.093 & 0.386 \\
\hline A2 & 0.088 & 0.545 \\
\hline A3 & 0.097 & 0.267 \\
\hline A4 & 0.106 & 0.000 \\
\hline A5 & 0.097 & 0.288 \\
\hline A6 & 0.072 & 1.000 \\
\hline
\end{tabular}

Tam çarpımsal yaklaşıma göre Eşitlik 14 ve 15 kullanılarak elde edilen fayda ve normalize fayda değerleri ise Tablo 10'daki gibi elde edilmiștir.

Tablo 10: Tam çarpımsal yaklaşıma göre 2020 yılı için elde edilen sonuç değerleri

\begin{tabular}{|c|c|c|}
\hline & $u_{i}$ & $u_{i}^{\prime}$ \\
\hline A1 & $1.493 \mathrm{E}-06$ & 0.022 \\
\hline A2 & $4.977 \mathrm{E}-09$ & 0.000 \\
\hline A3 & $3.164 \mathrm{E}-07$ & 0.005 \\
\hline A4 & $6.688 \mathrm{E}-05$ & 1.000 \\
\hline A5 & $3.474 \mathrm{E}-07$ & 0.005 \\
\hline A6 & $4.491 \mathrm{E}-06$ & 0.067 \\
\hline
\end{tabular}

Toplamsal yaklaşıma göre ise alternatiflerin fayda değerleri Eşitlik 16 ve 17 kullanılarak elde edilmiş olup sonuçları Tablo 11'de paylaşılmıştır.

Tablo 11: Toplamsal yaklaşıma göre 2020 yılı için elde edilen sonuç değerleri

\begin{tabular}{|c|c|c|}
\hline & $v_{i}$ & $v_{i}^{\prime}$ \\
\hline A1 & 2.679 & 0.289 \\
\hline A2 & 2.513 & 0.226 \\
\hline A3 & 1.991 & 0.029 \\
\hline A4 & 4.562 & 1.000 \\
\hline A5 & 1.915 & 0.000 \\
\hline A6 & 3.525 & 0.608 \\
\hline
\end{tabular}

MULTIMOOSRAL yönteminde beşinci ve sonuncu değerlendirme yaklaşımı olan logaritmik yaklaşıma göre elde edilen sonuçlara Eşitlik 18 ve 19 kullanılarak ulaşılmış olup, fayda değerleri Tablo 12'deki gibidir. 
Tablo 12: Logaritmik yaklaşıma göre 2020 yılı için elde edilen sonuç değerleri

\begin{tabular}{|c|c|c|}
\hline & $k_{i}$ & $k_{i}^{\prime}$ \\
\hline A1 & 10.770 & 0.273 \\
\hline A2 & 9.026 & 0.000 \\
\hline A3 & 10.819 & 0.280 \\
\hline A4 & 15.424 & 1.000 \\
\hline A5 & 10.626 & 0.250 \\
\hline A6 & 12.619 & 0.562 \\
\hline
\end{tabular}

Son olarak MULTIMOOSRAL yaklaşımının nihai sıralaması için Eşitlik 20 kullanılarak alternatiflerin fayda değerleri hesaplanmış olup, sonuç değerleri Tablo 13'te aktarılmıştır.

Tablo 13: MULTIMOOSRAL yöntemine göre 2020 yılı için alternatiflerin sıralaması

\begin{tabular}{|c|c|c|c|c|c|c|c|}
\hline & $m_{i}^{\prime}$ & $t_{i}^{\prime}$ & $u_{i}^{\prime}$ & $v_{i}^{\prime}$ & $k_{i}^{\prime}$ & $S_{i}$ & Sira \\
\hline A1 & 0.481 & 0.386 & 0.022 & 0.289 & 0.273 & 1.451 & 3 \\
\hline A2 & 0.575 & 0.545 & 0.000 & 0.226 & 0.000 & 1.346 & 4 \\
\hline A3 & 0.037 & 0.267 & 0.005 & 0.029 & 0.280 & 0.618 & 5 \\
\hline A4 & 1.000 & 0.000 & 1.000 & 1.000 & 1.000 & 4.000 & 1 \\
\hline A5 & 0.000 & 0.288 & 0.005 & 0.000 & 0.250 & 0.543 & 6 \\
\hline A6 & 0.777 & 1.000 & 0.067 & 0.608 & 0.562 & 3.013 & 2 \\
\hline
\end{tabular}

2019 Yılı için de tüm firmaların MULTIMOOSRAL yaklaşımına göre finansal performansları analiz edilmiş ve sonuçları Tablo 14'de verilmiştir.

Tablo 14: MULTIMOOSRAL yöntemine göre 2019 yılı için alternatiflerin sıralaması

\begin{tabular}{|c|c|c|c|c|c|c|c|}
\hline & $m_{i}^{\prime}$ & $t_{i}^{\prime}$ & $u_{i}^{\prime}$ & $v_{i}^{\prime}$ & $k_{i}^{\prime}$ & $S_{i}$ & Sira \\
\hline $\mathrm{A} 1$ & 0.427 & 0.520 & 0.075 & 0.194 & 0.237 & 1.452 & 4 \\
\hline $\mathrm{A} 2$ & 0.696 & 0.847 & 0.000 & 0.158 & 0.000 & 1.701 & 3 \\
\hline $\mathrm{A} 3$ & 0.000 & 0.284 & 0.029 & 0.000 & 0.234 & 0.547 & 5 \\
\hline $\mathrm{A} 4$ & 1.000 & 0.000 & 1.000 & 1.000 & 1.000 & 4.000 & 1 \\
\hline $\mathrm{A} 5$ & 0.124 & 0.027 & 0.023 & 0.069 & 0.261 & 0.503 & 6 \\
\hline $\mathrm{A} 6$ & 0.852 & 1.000 & 0.131 & 0.508 & 0.414 & 2.905 & 2 \\
\hline
\end{tabular}

Tablo 13 ve 14'teki MULTIMOOSRAL yaklaşımı ile firmaların finansal performans analizi sıralamalarında 2019 ve 2020 yılı için A4 birinci sırada yer alırken A5 her iki yılda da son sırada kendine yer bulmuştur. 2019 ve 2020 yılında sıralamalardaki tek değişiklik 2019 yılında üçüncü ve 
dördüncü sıralarda yer alan A2 ve A1'in yerlerini 2020 yılında değiştirmesiyle gözlenmiștir. Sonuçlarda dikkat çeken bir husus ise A4 firmasının her iki yılda da MULTIMOOSRAL'ı oluşturan referans noktası yaklaşımı haricinde diğer dört yaklaşımda birinci sırada yer alırken referans noktası yaklaşımına göre ise her iki sene için de son sırada kendine yer bulmasıdır. Buna neden olarak referans noktası yaklaşımının diğer yaklaşımlardan farklı olarak referans noktalarına maksimum uzaklığa göre alternatifleri sıralamasıdır. Referans noktası yaklaşımında her iki yıl için de ağırlıklı maksimum uzaklık F07 kriterinde ortaya çıkmış ve burada en zayıf değere sahip A4 firması bu nedenle son sırada yer almıştır. Fakat diğer dört yaklașımda birinci olmasından dolayı A4 yine de nihai sıralamada birinci sırada kalmayı başarmıştır. MULTIMOOSRAL yaklaşımı bu açıdan bir ÇKKV metodunda ne kadar çok yaklaşım bütünleştirilirse ÇKKV'nın etkinliğinin o ölçüde artacağına bir örnek olarak gösterilebilir durumdadır.

\section{DUYARLILIK ANALİZi}

Duyarlılık analizi ÇKKV'de elde edilen sonucun girdi değerlerindeki değişime olan tepkisini anlamlandırmak için sıklıkla gerçekleştirilen bir yaklaşımdır. Triantaphyllou ve Sánchez (1997) tarafından yapılan çalışmada toplamsal ve çarpımsal yaklaşımlar kullanılan metotlarda sıra değişimleri için gerekli olan yeni kriter ağırlıkları belirlemeyi içeren yaklaşımlar incelenmiştir.

5 farklı tipte sıralama fonksiyonu barındıran ve bunların birleşiminden olan MULTİMOOSRAL yönteminde alternatif sıralamaları değişimi için gerekli olan kriter ağırlığı belirleme işleminin pratik olarak zorluğu nedeniyle Fattahi ve Khalilzadeh (2018) tarafından önerilen kriter ağırlıklarının dört ayrı senaryoda farklılaştırarak duyarlılığın incelendiği analiz yaklaşımı bu çalışmada da tercih edilmiştir.

Burada çalışmaya özgü olarak ilk durum, problem çözümünde ortaya çıkan durum olan karlılık oranlarının en yüksek ağırlığa sahip olduğu durumdur. Diğer durumlarda ise karlılık oranlarının ağırlıklarının sırasıyla likitide, kaldıraç ve sermaye yapısı oranları ile yer değiştirmesi ile oluşturulmuş olup Tablo 15'te ilgili durumlar için kriter ağırlıkları verilmiştir. Bu sayede belirli tipte finansal oranların daha ön planda olduğunda sıralama değişimleri olup olmadığı incelenmiştir.

Tablo 15: Oluşturulan senaryolara göre kriter ağırlıkları

\begin{tabular}{|c|c|c|c|c|c|c|c|c|}
\hline & F01 & $\mathrm{FO} 2$ & FO3 & $\mathrm{FO} 4$ & F05 & F06 & F07 & F08 \\
\hline \multicolumn{9}{|c|}{2019 YILI Kriter Ağırlıkları } \\
\hline Durum 1 & 0.12 & 0.10 & 0.13 & 0.10 & 0.10 & 0.14 & 0.16 & 0.16 \\
\hline Durum 2 & 0.16 & 0.16 & 0.13 & 0.10 & 0.10 & 0.14 & 0.12 & 0.10 \\
\hline Durum 3 & 0.12 & 0.10 & 0.16 & 0.16 & 0.10 & 0.14 & 0.13 & 0.10 \\
\hline Durum 4 & 0.12 & 0.10 & 0.13 & 0.10 & 0.16 & 0.16 & 0.10 & 0.14 \\
\hline \multicolumn{9}{|c|}{2020 YILI Kriter Ağırlıkları } \\
\hline Durum 1 & 0.11 & 0.09 & 0.14 & 0.10 & 0.10 & 0.14 & 0.16 & 0.16 \\
\hline Durum 2 & 0.16 & 0.16 & 0.14 & 0.10 & 0.10 & 0.14 & 0.11 & 0.09 \\
\hline Durum 3 & 0.11 & 0.09 & 0.16 & 0.16 & 0.10 & 0.14 & 0.14 & 0.10 \\
\hline Durum 4 & 0.11 & 0.09 & 0.14 & 0.10 & 0.16 & 0.16 & 0.10 & 0.14 \\
\hline
\end{tabular}

Senaryolara göre elde edilen alternatif sıralamaları ise Tablo 16'da verilmiştir. Sıralamalarda farklılıklar oluşmuş olsa da 2019 ve 2020 yıllarında Durum 1 için ilk ve ikinci sırada yer alan A4 ve A6 firmaları, 2019 yılında A6'nın durum 4'te üçüncülüğe düşmesi dișındaki tüm diğer durumlarda da aynı yerlerini korumuşlardır. Fakat alt sıralamalardaki firmaların sıklıkla yer değiștirdikleri 
gözlenmiştir. Bu durumda A4 ve A6'nın çalışmada kullanılan finansal performans göstergeleri bakımından diğerlerinden daha farklı ve kendi klasmanlarında bulunduğu düşünülmektedir. Öte yandan Durum 1 ile diğer durumlar açısından sıralamalar bakımından ilişki düzeyi incelenmek adına Spearman sıra korelasyon testi yapılmış olup, Durum 2, 3 ve 4 için bu korelasyon katsayı değerleri, 2019 yılı için sırasıyla $0.6,0.6571$ ve 0.5429 olurken 2020 yılı için ise $0.0583,0.9429$ ve 0.8286 şeklinde elde edilmiştir. Buna göre Durum 1 ile diğer durumlar arasında en az orta düzey sıralama benzerliği bulunduğu görülmüştür.

Tablo 16: Oluşturulan senaryolara göre alternatiflerin sıralamaları

\begin{tabular}{|c|c|c|c|c|c|c|}
\hline & A1 & A2 & A3 & A4 & A5 & A6 \\
\hline \multicolumn{7}{|c|}{2019 Yll Alternatif Siralamalar } \\
\hline Durum 1 & 4 & 3 & 5 & 1 & 6 & 2 \\
\hline Durum 2 & 3 & 6 & 5 & 1 & 4 & 2 \\
\hline Durum 3 & 3 & 6 & 4 & 1 & 5 & 2 \\
\hline Durum 4 & 2 & 6 & 4 & 1 & 5 & 3 \\
\hline \multicolumn{7}{|c|}{2020 Yll Alternatif Siralamaları } \\
\hline Durum 1
\end{tabular}

\section{SONUÇ}

Firmaların etkinliğini gösteren ana öğelerden finansal performans sonuçları, firmaların ve içinde bulundukları sektörün ve hatta ekonominin tamamını kapsayan etkilere sahip olmaktadır. Bununla birlikte yapılan analizler sonucunda firmalar gelecek planlarını gözden geçirebilmekte ve buna göre gerekli atılımları ve tedbirleri gerçekleștirebilmektedirler. Finansal performans bakımından gösterilen zayıf performans uzun dönemde firmaların etkinliğini azaltabilmektedir. Zira sektör bazında rekabet edebilirlik gücü finansal başarı ile doğru orantılı olmaktadır. Bu nedenlerden ötürü finansal performans ölçümü firmalar açısından gerekli görülmektedir.

Finansal performans değerlendirmesinde alan yazında çoğunlukla tercih edilen ve firmalar tarafından da anlamlı bulunan finansal oranlar belirleyici olmaktadır. Fakat bu oranların hangi önemde analize dahil edileceği konusunda bir uzlaşma oluşmamıştır. Çalışmalarda bu sebeple objektif kriter ağırlıklandırma yaklaşımlarından yararlanılması yaygınlaşmıştır. Bu çalışmada kullanılan CRITIC yöntemi de bu yaklaşımlardan bir tanesidir. Kriterler arası ve kriter içi dağılımları birlikte ele alan yapısı ile yöntem daha kapsayıcı sonuçlar üretebilmektedir. Öte yandan çalışmada firmaları sıralamada kullanılan MULTIMOOSRAL ise beş farklı sıralama tekniğini barındırması ve bunları kendine özgü biçimde uzlaştırması ile ÇKKV metodolojisine özgün bir yaklaşım olarak dahil olmuştur.

Çalışmada CRITIC ve MULTIMOOSRAL yaklaşımlarının bir arada ilk kez kullanımı ile literatüre katkı sağlanmak amaçlanmış olup, BIST Sigorta Endeksi kapsamında yer alan firmaların finansal performans analizinde yöntemlerle elde edilen sonuçların gösterdiği üzere oldukça başarılı olmuşlardır. Zira CRITIC ile yıllara göre istikrarlı sonuçlar üretilebilirken MULTIMOOSRAL ile de kullanılan beş yaklaşımdan herhangi bir tanesinin diğerlerinden sapan sonuçlara sahip olmasının 
etkisi de kullanılan yaklaşım sayısı çokluğu nedeniyle en aza indirgenmiştir. Öte yandan yapılan duyarlılık analizi ile bu sonuçlar pekişmiştir. Literatürde yer alan diğer ÇKKV yaklaşımlarından barındırdığı sıralama yaklaşımı sayısı ve çeşidi bakımından ayrışan MULTIMOOSRAL'ın finansal performans analizi problemlerinde yüksek başarım sağlayabileceği görülmüștür.

Geleceğe bakıldığında, CRITIC ve MULTIMOOSRAL yaklaşımlarının birlikte ve ayrı ayrı farklı ÇKKV problemlerinde kullanılabileceği ve diğer yöntemlerle kıyaslamalarının yapılabileceği öngörülmektedir. 


\section{KAYNAKÇA}

Acar, M. (2019). Finansal Performansin Belirlenmesinde Ve Siralanmasinda Topsis Çok Kriterli Karar Verme Yönteminin Kullanilmasi: Bist Sigorta Şirketleri Uygulamasi. Finansal Arastirmalar ve Calismalar Dergisi, 11(21), 136-162.

Altan, İ. M., ve Yildirim, M. (2019). Sigorta Sektörünün Finansal Performansının Entropi Ağırlıklandırmalı TOPSIS Yöntemiyle Analizi ve Değerlendirilmesi. İnsan ve Toplum Bilimleri Araştırmaları Dergisi, 8(1), 345-358.

Aytekin, A., ve Karamaşa, Ç. (2017). Analyzing financial performance of insurance companies traded in BIST via fuzzy Shannon's entropy based fuzzy topsis methodology. Alphanumeric Journal, 5(1), 71-84.

Cummins, J. D., Tennyson, S., ve Weiss, M. A. (1999). Consolidation and efficiency in the US life insurance industry. Journal of banking \& Finance, 23(2-4), 325-357.

Çakır, S. (2016). Türk sigortacılık sektöründe çok kriterli karar verme teknikleri (ÇKKV) ile performans ölçümü: BIST uygulaması. Çukurova Üniversitesi İktisadi ve İdari Bilimler Fakültesi Dergisi, 20(1), 127-147.

Diakoulaki, D., Mavrotas, G., ve Papayannakis, L. (1995). Determining objective weights in multiple criteria problems: The critic method. Computers \& Operations Research, 22(7), 763-770.

Dwivedi, R., Prasad, K., Mandal, N., Singh, S., Vardhan, M., ve Pamucar, D. (2021). Performance evaluation of an insurance company using an integrated Balanced Scorecard (BSC) and BestWorst Method (BWM). Decision Making: Applications in Management and Engineering, 4(1), 33-50.

Fattahi, R., ve Khalilzadeh, M. (2018). Risk evaluation using a novel hybrid method based on FMEA, extended MULTIMOORA, and AHP methods under fuzzy environment. Safety science, 102, 290300.

Işık, Ö. (2019). Türkiye'de hayat dışı sigorta sektörünün finansal performansının CRITIC tabanlı TOPSIS ve MULTIMOORA yöntemiyle değerlendirilmesi. Business \& Management Studies: An International Journal, 7(1), 542-562.

Jahan, A., Mustapha, F., Sapuan, S. M., Ismail, M. Y., ve Bahraminasab, M. (2012). A Framework For Weighting Of Criteria In Ranking Stage Of Material Selection Process, The International Journal of Advanced Manufacturing Technology, 58(1), 411-420.

Krishnan, A. R., Kasim, M. M., Hamid, R., ve Ghazali, M. F. (2021). A Modified CRITIC Method to Estimate the Objective Weights of Decision Criteria. Symmetry, 13(6), 973.

Kula, V., Kandemir, T., ve Baykut, E. (2016). Borsa istanbul'da işlem gören sigorta ve BES şirketlerinin finansal performansının gri ilişkisel analiz yöntemi ile incelenmesi. Afyon Kocatepe Üniversitesi İktisadi ve İdari Bilimler Fakültesi Dergisi, XVIII(1), 37-53.

Mandić, K., Delibašić, B., Knežević, S., ve Benković, S. (2017). Analysis of the efficiency of insurance companies in Serbia using the fuzzy AHP and TOPSIS methods. Economic research-Ekonomska istraživanja, 30(1), 550-565.

Ömürbek, N., ve Özcan, A. (2016). BİST’de işlem gören sigorta şirketlerinin MULTIMOORA yöntemiyle performans ölçümü. Uluslararası İşletme, Ekonomi ve Yönetim Perspektifleri Dergisi, 1(2), 64-75. 
Perçin, S., ve Sönmez, Ö. (2018). Bütünleşik Entropi Ağirlik Ve TOPSIS Yöntemleri Kullanilarak Türk Sigorta Şirketlerinin Performansinin Ölçülmesi. Uluslararası İktisadi ve İdari İncelemeler Dergisi, 565-582.

Shen, K. Y., Hu, S. K., ve Tzeng, G. H. (2017). Financial modeling and improvement planning for the life insurance industry by using a rough knowledge based hybrid MCDM model. Information Sciences, 375, 296-313.

Tayyar, N., Yapa, K., Durmuş, M., ve Akbulut, İ. (2018). Referans İdeal Metodu ile Finansal Performans Analizi: BİST Sigorta Şirketleri Üzerinde Bir Uygulama. İnsan ve Toplum Bilimleri Araştırmaları Dergisi, 7(4), 2490-2509.

Torbati, A. R., ve Sayadi, M. K. (2018). A new approach to investigate the performance of insurance branches in Iran using best-worst method and fuzzy inference system. Journal of Soft Computing and Decision Support Systems, 5(4), 13-18.

Triantaphyllou, E., ve Sánchez, A. (1997). A sensitivity analysis approach for some deterministic multi-criteria decision-making methods. Decision sciences, 28(1), 151-194.

Ulutaş, A., Stanujkic, D., Karabasevic, D., Popovic, G., Zavadskas, E. K., Smarandache, F., ve Brauers, W. K. (2021). Developing of a Novel Integrated MCDM MULTIMOOSRAL Approach for Supplier Selection. Informatica, 32(1), 145-161.

Ünal, E. A. (2019). Bütünleşik Entropi Ve Edas Yöntemleri Kullanilarak Bist Sigorta Şirketlerinin Performansinin Ölçülmesi. Finans Ekonomi ve Sosyal Araştırmalar Dergisi, 4(4), 555-566.

Wu, H. W., Zhen, J., ve Zhang, J. (2020). Urban rail transit operation safety evaluation based on an improved CRITIC method and cloud model. Journal of Rail Transport Planning \& Management, 16, 100206.

Yayla, Ș. O. (2019). Sigortacılık ve Türkiye'de Sigorta Sektörünün Durumu. Liberal Düşünce Dergisi, 24(94), 107-125.

Zhao, M., Wang, X., Yu, J., Xue, L., ve Yang, S. (2020). A construction schedule robustness measure based on improved prospect theory and the Copula-CRITIC method. Applied Sciences, 10(6), 2013.

Žižović, M., Miljković, B., ve Marinković, D. (2020). Objective methods for determining criteria weight coefficients: A modification of the CRITIC method. Decision Making: Applications in Management and Engineering, 3(2), 149-161. 


\section{EXTENDED ABSTRACT}

\section{Financial Analysis Based on CRITIC and MULTIMOOSRAL Techniques in BIST Insurance Index}

\section{Introduction}

The insurance service, which is provided with a certain premium payment, has an approach that takes the possible big financial losses from the person or company and shares it to the whole economy. Insurance companies are one of the important structures that provide stability in the economy by protecting their customers from damages that may bring them to the brink of bankruptcy in some cases, depending on the size of the damage that may occur in this respect. On the other hand, it uses the premiums it collects in the field of finance and transfers long-term resources to the economy (Altan and Yıldırım, 2019: 347). While insurance companies enable individuals to save regularly and effectively in both developed and developing economies, they also support the realization of investments in the country with the funds they create (Ișik, 2019: 543). The insurance sector, whose size in the financial structure of the Turkish economy is constantly increasing, also has a positive effect on economic development. Since the effectiveness of insurance companies is directly proportional to the benefit provided by the insurance sector, it is very important to analyse the financial performance of insurance companies and to highlight possible improvement targets for the stability of the sector and the trust of service buyers (Ünal, 2019: 556).

\section{Data Set and Method}

In this study, it is aimed to effectively evaluate the financial performance of the companies that are subject to the BIST insurance index by using financial ratios. For this purpose, the criteria in the problem, which is considered as the Multi-Criteria Decision Making (MCDM) model, are prioritized with the help of CRITIC (Criteria Importance Through Intercriteria Correlation), which is an approach that handles both inter-criteria correlation and intra-criteria deviations together. On the other hand, performance rankings were carried out with MULTIMOOSRAL (Multi-Multi-Objective Optimization on the basis of Simple Ratio Analysis), which has never been used in Turkish literature before and uses five basic calculation techniques. The fact that the method has not been used in the field of financial performance before and that it is used for the first time in an integrated manner with an objective criterion weighting approach such as CRITIC is considered as the contribution of the study to the literature.

\section{Empirical Findings}

By using the MULTIMOOSRAL approach, A4 ranked first in the financial performance analysis rankings of companies for 2019 and 2020, while A5 took the last place in both years. The only change in the rankings in 2019 and 2020 was observed when A2 and A1, which were in the third and fourth places in 2019, were replaced in 2020. A striking point in the results is that A4 company ranks first in all four approaches except for the reference point approach that creates MULTIMOOSRAL in both years, while it ranks last in both years according to the reference point approach. The reason for this is that the reference point approach, unlike other approaches, ranks the alternatives according to the maximum distance to the reference points. In the reference point approach, the weighted maximum distance for both years appeared in the F07 criterion, and the company with the weakest value, A4, was in the last place for this reason. However, due to being first in the other four approaches, A4 still managed to stay in first place in the final ranking. In this respect, the MULTIMOOSRAL approach can be shown as an example that the more approaches are integrated in a MCDM method, the more effective the MCDM will be. 


\section{Discussion and Conclusion}

In the study, it was aimed to contribute to the literature by using the CRITIC and MULTIMOOSRAL approaches together for the first time, and as the results obtained with the methods in the financial performance analysis of the companies included in the BIST Insurance Index showed, they were quite successful. Because with CRITIC, stable results can be produced over the years, while the effect of any of the five approaches used with MULTIMOOSRAL to have results deviating from the others is minimized due to the large number of approaches used. On the other hand, these results were reinforced by the sensitivity analysis. It has been seen that MULTIMOOSRAL, which differs from other MCDM approaches in the literature in terms of the number and variety of ranking approaches, can provide high performance in financial performance analysis problems. 